\title{
DIREITO E MORAL: POSITIVISMO, NÃO POSITIVISMO E APLICAÇÃO DAS NORMAS JURÍDICAS
}

\author{
Anizio Pires Gavião Filho*
}

\section{Resumo}

A investigação trata da relação entre o Direito e a Moral. As teses do positivismo e do não positivismo. Os juízes decidem com base em suas concepções sobre a natureza do Direito e de como configuram a relação entre o Direito e a Moral. A presença de princípios morais na natureza e no conceito de Direito, na identificação das fontes do Direito e na interpretação das normas jurídicas faz necessárias avaliações morais na aplicação do Direito. Com isso, fica colocada a exigência da apresentação de razões conforme as regras da racionalidade discursiva. Pesquisa bibliográfica.

Palavras chaves: positivismo; não positivismo; moral; ponderação; justificação.

\section{LAW AND MORAL: POSITIVISMO, NON-POSITIVISM AND APLICATION OF LEGAL NORMS}

\begin{abstract}
The investigation deals with the relation between Law and Morals. The theses of positivism and non-positivism. Judges decide based on their views on the nature of Law and how they shape the relationship between law and morality. The presence of moral principles in nature and in the concept of Law, in the identification of the sources of Law and in the interpretation of legal norms makes necessary moral evaluations in the application of Law. With this, the requirement of presenting reasons according to the rules of discursive rationality is placed. Bibliographic research.
\end{abstract}

Key words: positivism; non- positivism; moral; balancing; justification.

\footnotetext{
* Doutor em Direito, UFRGS. Professor Titular da Faculdade de Direito da Fundação Escola Superior do Ministério Público - FMP - disciplinas de Teoria da Argumentação Jurídica e Hermenêutica Jurídica. Professor Coordenador do Programa de Pós-graduação Stricto Sensu - Mestrado Acadêmico da FMP. Procurador de Justiça, RS. E-mail: piresgaviao@hotmail.com. Endereço postal: Av. Juca Batista, 9000/1125, Belém Novo, Porto Alegre, CEP 91781600, Rio Grande do Sul.
} 


\section{Introdução}

As discussões em torno da natureza do Direito, da aplicação do Direito e da fundamentação da aplicação do Direito para resolver casos práticos são ainda colocadas justificadamente. As controvérsias sobre a natureza do Direito são intensas. Para atender as pretensões de uma ideia geral, três questões podem ser colocadas sobre esse tema. O que é Direito? Qual é o conceito de Direito? Qual é a relação entre o Direito e a Moral?

Não são poucas as concepções e teorias sobre a natureza do Direito. Elas apresentam respostas diferentes para as discussões que dizem respeito à natureza do Direito e à relação entre o Direito e a Moral.

Mas por que isso importa ou qual é a relevância de uma discussão sobre a natureza do Direito ou sobre a relação entre o Direito e a Moral? Qual é a contribuição das discussões sobre a natureza do Direito e sobre a relação entre o Direito e Moral para a resolução de casos práticos pelos juízes e tribunais?

O que se pretende sustentar é que essas discussões impactam diretamente na interpretação e aplicação das normas jurídicas pelos juízes e tribunais para resolver casos concretos. Os juízes e tribunais decidem sobre as questões práticas dos casos concretos que lhes são apresentados sob a base das suas concepções sobre a natureza do Direito e de como configuram a relação entre o Direito e a Moral. Então, importa decisivamente bem compreender as questões em torno da natureza do Direito e da relação entre o Direito e a Moral.

Mas são igualmente acirradas as discussões em torno da aplicação e fundamentação racional do Direito para a resolução de questões práticas nos casos concretos. Trata-se de um assunto extremamente complexo. Isso porque, no mínimo, envolve dois temas centrais: o raciocínio jurídico e a fundamentação racional da interpretação e aplicação do Direito. Como é ou deve ser o raciocínio jurídico? Qual é a estrutura do raciocínio jurídico de aplicação das normas jurídicas na resolução das questões práticas colocadas nos casos concretos? Enfim, qual é a metodologia de aplicação das normas jurídicas?

E, finalmente, o que dizer sobre a fundamentação racional da interpretação e aplicação das normas jurídicas na resolução das questões práticas? Esse tema remete para a justificação ou fundamentação racional das decisões dos juízes e tribunais. Aqui, trata-se disto. Fundamentação da interpretação e aplicação das normas jurídicas, que diz com a apresentação de razões e argumentos para a justificação da proposição normativa individual concreta dada para a solução de uma questão prática. Racionalidade da interpretação e aplicação das normas 
jurídicas, que remete e pressupõe diretamente a possibilidade ou não de aplicação racional do Direito na solução de questões práticas e que são possíveis decisões judiciais racionais. Nesse ponto, o desafio não é pequeno notadamente porque pretende unir a aplicação de normas jurídicas nas decisões judiciais para a solução de questões práticas nos casos concretos e a aspiração de racionalidade de juízos de dever ou de proposições normativas.

A discussão será desenvolvida nesta estrutura.

Em uma primeira parte, serão apresentadas as discussões sobre a natureza do Direito e a relação entre o Direito e Moral. Na segunda parte, a discussão terá por objeto a interpretação jurídica e a metodologia de aplicação das normas jurídicas. Na terceira parte, a temática será a fundamentação racional das decisões judiciais.

É certo que cada uma dessas partes não poderá receber aqui um tratamento detalhado, mas apenas mais amplo e geral, de modo suficiente para justificar que elas devem ser intrínseca e reciprocamente analisadas.

A metodologia da pesquisa é a da bibliográfica comparativa.

\section{A natureza e o conceito do Direito}

A discussão sobre a natureza do Direito remete para a questão sobre a relação entre o Direito e a Moral. Dela tratam as teses da separação e da conexão necessária.

Os positivistas defendem a tese da separação. Não há conexão necessária entre o Direito e a Moral. Não há conexão necessária entre a validade jurídica e o conteúdo moral. A validade nas normas jurídicas não depende de correção moral dessas normas jurídicas. Ao conceito e a natureza do Direito interessam apenas dois elementos: autoridade investida de poder para dar o ordenado juridicamente e eficácia social (HART, 1961, p. 185-186; WALUCHOW, 1994, p. 5-7; RAZ, 2009, p. 179-180). A validade do Direito é condicionada por esses fatos, independentemente de sua relação com a Moral (KELSEN, 2010, p. 86).

Os não positivistas defendem a tese da conexão necessária. A validade das normas jurídicas depende da correção quanto ao seu conteúdo. Somente são válidas as normas jurídicas cujo seu conteúdo está em conformidade com a moralidade. Ao conceito e a natureza do Direito interessam três elementos: investidura da autoridade, eficácia social e correção quanto ao conteúdo (ALEXY, 2002, p. 3-4).

O exame e as repercussões dessas duas teses podem ser melhor detalhados se olhadas as formas de positivismo e as formas de não positivismo. 
As formas de positivismo são o positivismo exclusivo e o positivismo inclusivo.

O positivismo exclusivo sustenta que a Moral não é critério para a identificação da validade das normas jurídicas. Na verdade, o positivismo exclusivo inclui a tese da separação na tese do fato social, atualmente entendida como a tese das fontes. Assim, para o positivismo exclusivo, Direito e Moral se acham necessariamente separados para a identificação das normas jurídicas válidas (RAZ, 2009, p. 179-180).

O positivismo inclusivo sustenta que a Moral não está necessariamente excluída, nem necessariamente incluída. A inclusão é contingente ou convencional. O resultado é que tanto no positivismo exclusivo como no inclusivo a relação entre o Direito e a Moral é determinada pelos fatos sociais, ou seja, pelo que é investido de autoridade e dotado de eficácia social (COLEMAN, 1982, p. 148-149). O positivismo inclusivo é ainda positivismo, pois diz que a relação entre o Direito e a Moral é apenas contingente. O positivismo inclusivo é o positivismo contemporâneo desenvolvido a partir da década de 1970, notadamente a partir do ataque de Dworkin formulado em O Modelo de Regras I (DWORKIN, 1978a, p. 14-45).

As formas de não positivismo são o não positivismo exclusivo, o não positivismo superinclusivo e o não positivismo inclusivo. O não positivismo contraria as duas formas de positivismo. As diferenças entre as formas de não positivismo resultam dos efeitos que defeitos morais implicam para a validade jurídica. A relação entre a validade jurídica e a extensão do defeito moral leva a três formas de não positivismo: a validade resulta totalmente comprometida; a validade é somente afetada em alguns casos e validade não é afetada pelos defeitos morais (ALEXY, 2015, p. 305).

Quais são as diferenças entre as três formas de não positivismo?

Para o não positivismo exclusivo, o defeito moral conduz a invalidade jurídica. Cuidase de um caso em que a validade jurídica resulta totalmente comprometida. Essa é a versão mais radical do não positivismo. Assim, por exemplo, a formulação de que as regras imorais não são juridicamente válidas. O não positivismo superinclusivo é o oposto do não positivismo exclusivo. Ele sustenta que a validade jurídica em nada é afetada pelos vícios morais das normas jurídicas. Essa versão do não positivismo parece ser uma forma de positivismo, mas não é (ALEXY, 2015, p. 306-307).

Em Alexy, a conexão entre o conceito de Direito e os elementos da moralidade é dada pelo argumento da pretensão de correção. O Direito promove pretensão de correção. O ordenamento jurídico como um todo, as normas jurídicas e as proposições normativas singulares das decisões judiciais de aplicação das normas jurídicas promovem pretensão de 
correção. Com isso está dada a relação de necessariedade do decretado autoritativamente de acordo com a ordem e com eficácia social e a correção quanto ao conteúdo (ALEXY, 2004, p. 164-165).

O sistema jurídico que não formula uma pretensão de correção, explícita ou implicitamente, não é um sistema jurídico. Assim, a pretensão de correção serve para classificar ou desclassificar um ordenamento como jurídico. Igualmente, as normas jurídicas isoladas e as decisões judiciais colocam sempre uma pretensão de correção. O fato de uma norma jurídica isolada ou de uma decisão judicial de aplicação de norma jurídica, eventualmente, não formular a pretensão de correção não desclassifica o sistema jurídico para um não jurídico, mas qualifica a decisão judicial ou a norma como um defeito. Trata-se, apenas, de casos de normas jurídicas ou de decisões judiciais defeituosas ou imperfeitas (ALEXY, 2000, p. 144).

Então, pode-se afirmar que há dois tipos de conexão entre o Direito e Moral. Conexão classificatória e conexão qualificatória. O efeito de uma conexão classificatória é a perda da validade jurídica. Um sistema jurídico injusto não pode ser classificado com jurídico. O efeito de uma conexão qualificatória é a falibilidade ou viciosidade jurídica. O defeito ou vício, contudo, não vai tão longe: a validade jurídica não é atingida. Eventualmente, abre-se a possibilidade de os tribunais anularem julgamentos injustos de juízes inferiores com base em tais normas jurídicas (ALEXY, 2015, p. 306).

O não positivismo inclusivo é uma forma intermediária entre o não positivismo exclusivo e não positivismo superinclusivo. Ele sustenta que os defeitos morais atingem a validade jurídica apenas sob algumas condições e em nada a afetam sobre outras condições. O não positivismo inclusivo pode ser expresso pela fórmula de Radbruch: “extrema injustiça não é lei” (RADBRUCH, 1971, p. 14). Os defeitos morais somente atingem a validade jurídica se, e somente se, o limite da injustiça extrema é ultrapassado. As normas jurídicas cuja injustiça não ultrapassa o limite da extrema injustiça são válidas. Essas normas jurídicas são moral e juridicamente defeituosas, mas normas jurídicas válidas (RADBRUCH, 1971, p. 14-15; ALEXY, 2015, p. 306).

Isso representa o comprometimento do não positivismo inclusivo com a positividade: compromisso com o dado autoritativamente conforme o ordenado juridicamente e detém eficácia social.

A fórmula de Radbruch representa uma rejeição à tese positivista de que cada conteúdo qualquer pode ser Direito (KELSEN, 1960, p. 201). O positivismo de Kelsen diz que a justiça ou correção moral não é um critério para determinar a validade das normas jurídicas, também 
porque não existe uma justiça absoluta, mas apenas relativa. Se essas normas jurídicas foram dadas conforme o procedimento definido no ordenamento jurídico estabelecido na constituição e são socialmente eficazes, então se trata de Direito válido (KELSEN, 2010, p. 92). É o caso das normas jurídicas da apartheid sul-africana. Para o positivismo, essas normas são válidas. Para o positivismo inclusivo, igualmente, as normas são válidas, pois o Direito positivo não se refere a princípios morais que vedam essas normas. Para o não positivismo, a validade dessas normas depende da ponderação entre o princípio da segurança jurídica e o princípio da justiça (ALEXY, 2015, p. 314).

O princípio da segurança jurídica sustenta a formulação de que as normas jurídicas discriminatórias do Estado totalitário são válidas. O princípio da justiça diz que elas são inválidas, porque extremamente injustas. Na ponderação de princípios, no caso, o grau da intensidade de intervenção no princípio da justiça é extremamente alto. Justiça corresponde a direitos humanos e, então, no caso, a intervenção nos direitos humanos é extrema. Não reconhecer a invalidade dessas normas é uma intervenção extrema nos direitos humanos. Por outro lado, a invalidade dessas normas não seria uma intervenção extrema no princípio da segurança jurídica. Mesmo em Estados totalitários, um grande número de normas não ultrapassa o limite da extrema injustiça. Esse é o resultado da ponderação, que reflete a fórmula do Radbruch. É o caso do não positivismo inclusivo (ALEXY, 2015, p. 314).

A partir disso, podem ser colocadas as seguintes questões. Por que essas formulações sobre a natureza do Direito e a validade das normas jurídicas importam quando assunto diz com interpretação e aplicação do Direito para a resolução das questões práticas dos casos concretos? A partir da formulação de que os juízes e tribunais devem aplicar as normas jurídicas, como justificar casos em que normas jurídicas não expressamente declaradas inválidas não são aplicadas?

Desde já, deve ficar claro que não se trata de casos em que há dúvida ou divergência sobre o significado a ser atribuído ao texto da disposição jurídica. A questão colocada, portanto, não diz com a indeterminação normativa resultante de eventual vagueza, ambiguidade ou abertura valorativa das palavras empregadas no texto da disposição jurídica.

Normalmente, as razões empregadas para justificar essas decisões são lastreadas no argumento da justiça ou correção quanto ao conteúdo, tendo como base as circunstâncias do caso concreto. Então, nesses casos, argumentos morais são centrais e decisivos para justificar a chamada justiça do caso concreto. Com isso, o resultado é o reconhecimento de uma conexão entre o Direito e a Moral. 
Decisões desse tipo dificilmente podem ser justificadas pelo positivismo exclusivo. Mas elas podem ser justificadas pelo positivismo inclusivo e por todas as formas do não positivismo. O positivismo inclusivo não nega a possibilidade de conexão entre o Direito e a Moral, apenas diz que ela é contingente e não necessária como pretendem todas as formas do não positivismo. O não positivismo inclusivo parece a forma que melhor pode justificar decisões do tipo antes mencionado.

É certo que não se deve identificar ou confundir teoria sobre a natureza e o conceito de Direito com uma teoria sobre a fundamentação da interpretação e aplicação do Direito. Aliás, essa é uma das principais críticas dirigidas contra Ronald Dworkin, que em seu ataque ao positivismo jurídico, na verdade, apresenta mais uma teoria sobre a decisão judicial - daí quem sabe a designação teoria da decisão, escolhidos por alguns autores brasileiros ${ }^{1}$ a partir da tradução da expressão inglesa adjucation theory - do que propriamente uma teoria sobre a natureza e o conceito de Direito (WALUCHOW, 1994, p. 24).

O não positivismo inclusivo requer a ponderação entre segurança jurídica e o princípio da justiça. Somente nos casos de extrema injustiça, quando o alto grau de intensidade de intervenção no princípio da justiça - injustiça acima de qualquer dúvida - justifica o alto grau de prejuízo ao princípio da segurança jurídica, os juízes e tribunais estão autorizados a deixar de aplicar uma norma jurídica válida. Na verdade, nesse caso, o princípio da justiça logra uma precedência sobre o princípio da segurança jurídica condicionada às circunstâncias da hipótese fática concreta. Mas, bem entendido, esse é o caso apenas em situações de extrema injustiça e não de qualquer injustiça.

Nos casos de injustiça não extrema, em que o limite extremo da injustiça não é alcançado, tem-se um defeito ou vício moral da norma jurídica, mas esse não é tal que possa justificar a invalidade jurídica.

Essas formulações podem levantar as objeções da discricionariedade, subjetividade e irracionalidade na interpretação e aplicação das normas jurídicas nas decisões judiciais. Essas questões somente podem ser superadas com uma fundamentação racional da interpretação e aplicação das normas jurídicas.

Uma fundamentação racional pressupõe compreender a metodologia do raciocínio jurídico, o que diz com as formas de aplicação das normas jurídicas.

\footnotetext{
${ }^{1}$ Ver Motta (2017) e Streck (2014).
} 


\section{As formas de aplicação das normas jurídicas}

A teoria dos princípios como desenvolvida primeiro por Ronald Dworkin e depois por Robert Alexy sugeriu que as normas jurídicas são aplicadas de modos distintos conforme se tratem de regras ou princípios. As regras são aplicadas de modo tudo ou nada, como indicou Ronald Dworkin (1998, p. 24). Ou, conforme Robert Alexy, as regras são aplicadas mediante subsunção (2007, p. 132).

É que as regras são determinações definitivas, devendo ser cumprido exatamente o determinado pela regra. Realizadas as condições de aplicação de uma regra, deve ser cumprido o fixado definitivamente pela regra. As regras são normas que ordenam definitivamente e, por isso mesmo, mandamentos definitivos, que devem ser cumpridos exatamente conforme o determinado (ALEXY, 2000, p. 295). Se uma regra vale, então, está ordenado fazer exatamente o fixado no espaço do fático e do juridicamente possível. As regras são normas que ordenam, proíbem ou permitem algo definitivamente ou autorizam algo definitivamente. O dever estabelecido pelas regras é sempre definitivo. Quando os pressupostos da regra estão cumpridos, produz-se a consequência jurídica estabelecida. Assim, quando uma regra vale e é aplicável, é ordenado fazer rigorosamente aquilo que ela determina. Do contrário, somente duas alternativas estão abertas: a regra deve ser declarada inválida e, assim, excluída do ordenamento jurídico ou deve ser inserida uma exceção na regra, criando-se, então, uma nova regra (GAVIÃO FILHO, 2010, p. 31).

A subsunção é o julgamento ou avaliação do intérprete aplicador do Direito de que uma determinada situação fática realiza todos os elementos constitutivos da hipótese normativa abstratamente dada.

Por isso mesmo, a subsunção já pressupõe a determinação do significado da disposição jurídica. Esse é o lugar da interpretação jurídica. Aqui não há espaço para tratar disto, mas interpretação jurídica é uma atividade argumentativa. O significado atribuído ao texto deve ser acompanhado de razões. Essas razões são os argumentos interpretativos formulados com base nos cânones clássicos da hermenêutica jurídica, somado a argumentos práticos gerais, onde ingressam inclusive argumentos morais. Pode ainda ser acrescido o papel dos círculos hermenêuticos conhecidos.

Os princípios apresentam uma dimensão de peso. Eles colidem uns com os outros e, nesses casos, o princípio que alcança maior peso constitui fundamento para a decisão do caso concreto (DWORKIN, 1998, p. 26). Segundo Alexy, os princípios são normas que ordenam 
que algo seja realizado em uma medida tão alta quanto possível relativamente às possibilidades fáticas e jurídicas. Os princípios são mandamentos a serem otimizados, de tal sorte que admitem cumprimento em diferentes graus, conforme as possibilidades fáticas e jurídicas - as possibilidades jurídicas são exatamente os princípios em sentido contrário. Os princípios contêm um dever ideal e, por isso mesmo, não contêm um dever definitivo, mas um dever prima facie. Como mandamentos ideais, exigem mais do que é possível realmente. Princípios colidem com outros princípios e, por isso, a forma típica de aplicação dos princípios é a ponderação. Somente a ponderação leva do dever prima facie ideal ao dever real e definitivo. Os princípios são mandamentos ideais que são cumpridos em graus conforme as possibilidades fáticas e jurídicas (ALEXY, 2000, p. 295).

Então, os princípios são aplicados mediante ponderação. Ela é o terceiro princípio parcial do princípio da proporcionalidade. A ponderação é constituída sob a base das duas leis da ponderação. A primeira diz que quanto maior o grau de intervenção ou prejuízo em um princípio, tanto maior deve ser o grau importância da realização de outro princípio (ALEXY, 2007, p. 133). A segunda diz que quanto o maior grau de intervenção ou prejuízo em um princípio, tanto maior deve ser o grau de segurança ou certeza das premissas empíricas apresentadas para justificar essa intervenção ou prejuízo (ALEXY, 2007, p. 150).

O resultado da ponderação é o estabelecimento de uma relação de precedência de um princípio sobre o outro, conforme as circunstâncias do caso concreto. Essa relação de precedência será sempre condicionada às circunstâncias do caso concreto. Estabelecida essa relação de precedência, tem-se a formulação de uma regra jurídica. Ela diz que está ordenada definitivamente a consequência jurídica estabelecida pelo princípio ganhador da primazia. Com isso, tem-se a passagem de direitos prima facie ou ideais para direitos definitivos, passíveis de exigibilidade judicial.

Essas formulações parecem sugerir que somente duas são as formas de aplicação das normas jurídicas. Elas são aplicadas mediante subsunção e ponderação. E mais, parecem indicar que as regras são aplicadas mediante subsunção e princípios mediante ponderação.

Isso não é acertado.

A aplicação das normas jurídicas, em grande número de casos, combina um conjunto de técnicas de decisão que vai muito além da subsunção e da ponderação. A aplicação de uma norma jurídica não está restrita às alternativas de subsunção de seguir uma regra jurídica nos casos fáceis ou de ponderação no sentido de um mandado de otimização em todos os outros casos, considerados difíceis. Ao lado da subsunção e da ponderação há uma série de outros 
métodos e de diferentes combinações de todas essas técnicas (POSCHER, 2012, p. 236-237). As formas de aplicação do Direito não são apenas subsunção e ponderação, mas, no mínimo, subsunção, analogia e ponderação. Essas três formas básicas estão intrinsecamente conectadas (ALEXY, 2015, p. 225). A estrutura formal da subsunção é representada pelo esquema dedutivo, que é a fórmula da subsunção. Por seu lado, a ponderação tem a fórmula peso como a sua estrutura formal. A aplicação do Direito por intermédio da comparação de casos tem a forma da analogia. Então, as normas jurídicas não são aplicadas somente mediante subsunção, somente mediante analogia ou somente mediante ponderação. Na verdade, essas três formas de aplicação de normas jurídicas são combinadas e complementares. No caso de analogia, uma vez formulada a regra jurídica, o próximo passo é a subsunção. No caso da ponderação, o resultado é a formulação de uma regra e o próximo passo é a subsunção da regra formulada.

Já na justificação da analogia uma ponderação de princípios pode ser requerida. $\mathrm{O}$ julgamento do Supremo Tribunal Federal (ADPF 132) no caso de reconhecimento de proteção jurídica à união estável entre pessoas do mesmo sexo é um exemplo de caso em que as razões de fundamentação indicam ponderação de princípios, analogia e subsunção.

Assim, para justificar essa formulação, as referências aos princípios da dignidade humana e da isonomia, a similaridade relevante, para fins de proteção jurídica, entre a união estável entre um homem e uma mulher e a união estável entre dois homens ou a união estável entre duas mulheres e, por fim, a aplicação mediante subsunção da regra formulada por analogia reconhecedora de que a união estável entre pessoas do mesmo sexo merece proteção jurídica.

Com isso, resultado provado que o procedimento de aplicação das normas jurídicas é uma combinação de subsunção, analogia e ponderação.

Diz-se que os princípios são aplicados mediante ponderação, mas o resultado da ponderação fica no meio do caminho do raciocínio jurídico de aplicação do Direito para a solução das questões práticas de casos concretos. A ponderação termina com o estabelecimento da relação de precedência condicionada de um princípio sobre o outro. O seu resultado é o estabelecimento de uma regra que diz que está definitivamente ordenada a consequência jurídica do princípio ganhador da primazia. Ora, trata-se de uma regra, cuja forma de aplicação é a subsunção. Então, no procedimento de interpretação e aplicação do Direito, tem-se antes ponderação e depois subsunção.

Ainda sobre a subsunção um último ponto.

Em algumas formulações a subsunção aparece como um caso de aplicação mecânica e irrefletida das normas jurídicas. Isso somente pode pretender correção nos casos de aplicação 
arbitrária e irracional do Direito. Contudo, que tal possa ser o caso em algumas decisões judiciais não está excluído. Entretanto, evidentemente, não é isso o que deve ser em um Estado de Direito constitucional democrático.

O julgamento da subsunção é uma atividade argumentativa em que devem ser apresentadas razões para justificar que a hipótese fática realiza os elementos descritos abstratamente na hipótese normativa no momento da interpretação jurídica. A subsunção é um assunto de justificação externa e não de justificação interna, pois se trata da justificação da escolha da premissa normativa do raciocínio jurídico.

Ela nada tem com a verificação da correção lógica dedutiva do raciocínio jurídico, que é assunto de justiça interna. Portanto, erra quem identifica a subsunção com uma operação lógico-dedutiva de aplicação das normas jurídicas. Insistir nisso revela desconhecimento sobre o que é subsunção e sobre o papel do dedutivismo no raciocínio jurídico. Esse tema, aliás, remete para o último ponto. Ele tratará da estrutura da fundamentação racional da interpretação e aplicação do Direito.

\section{Fundamentação racional}

A pretensão de fundamentação racional das decisões judiciais de interpretação e aplicação das normas jurídicas para resolver as questões práticas de casos concretos submetidos aos juízes e tribunais pressupõe, antes, que questões práticas sejam passíveis de resolução racional. Requer, então, que os juízos de dever das proposições normativas sejam passíveis de verdade.

Não são poucas as teorias que negam a racionalidade das discussões práticas: intuicionismo, emotivismo, determinismo, decisionismo e relativismo. Aqui, como não se mostra desejável ou adequado enveredar para esse assunto, será dado como pressuposto que os juízos de dever das proposições normativas podem ser justificados racionalmente. As questões práticas são passíveis de verdade no âmbito de um discurso racional. Apenas, essa verdade deve tomada no sentido de correção (HABERMAS, 1999, p. 285-286; HABERMAS, 1987, p. 39).

Um juízo de dever será correto quando se achar racionalmente justificado. Cuida-se, portanto, de uma racionalidade comunicativa ou argumentativa. Uma advertência deve ser feita. Não se trata de uma racionalidade absoluta, mas de uma possível. Um juízo de dever será correto se justificado por um discurso racional. 
No caso do discurso jurídico de interpretação e aplicação das normas jurídicas, a justificação do juízo de dever concreto de resolução da questão prática submetida aos juízes e tribunais será racional tanto quanto forem cumpridas as exigências e regras da argumentação jurídica.

Um olhar para a estrutura do raciocínio jurídico autoriza falar-se em justificação interna e justificação externa da proposição normativa particular dada em uma decisão judicial.

A justificação interna é o lugar da verificação da relação de encadeamento lógico dedutivo das premissas com a conclusão do raciocínio jurídico. As premissas normativas e fáticas devem ser colocas uma cadeia completa e livre e contradições de tal modo que a conclusão resulte dedutivamente justificada (ALEXY, 1995, p. 17). Esse é o núcleo dedutivo do raciocínio jurídico. Cuida-se da aplicação das regras da lógica ao raciocínio jurídico.

Contra isso é conhecida a objeção de que as normas jurídicas não se submetem às regras da lógica, pois as normas jurídicas não podem ser verdadeiras ou falsas, mas válidas ou inválidas. É que as regras da lógica somente podem ser aplicadas as proposições que podem ser verdadeiras ou falsas (KELSEN, 1979, p. 153). Efetivamente, no raciocínio jurídico não se pode afirmar que há uma relação de necessariedade lógica entre as premissas e conclusão. Isso porque um juiz pode aceitar como corretas as premissas que justificam a condenação de um réu e, mesmo assim, pode absolvê-lo. Nesse caso, pode-se afirmar que a decisão do juiz é irracional ou arbitrária. Mas, contudo, a decisão está dada. Não pode ser afirmado, como o exemplo deixa saber, que as premissas implicam necessariamente a conclusão. Com isso, aliás, fica provado que Direito é também decisão e ato de vontade.

Mas, contudo, isso não significa que as premissas do raciocínio jurídico não podem ser colocadas em uma cadeia dedutiva. Elas efetivamente não implicam o juízo de dever concreto, mas elas dizem qual ele deve ser. Então, as razões de justificação, que dizem qual deve ser a solução da questão prática do caso concreto, podem ser colocadas em encadeamento dedutivo (MacCORMICK, 2005, p. 55). Daí, então, poder se falar em justificação dedutiva.

$\mathrm{Na}$ justificação externa se trata da fundamentação de cada uma das premissas empregadas na justificação interna. No raciocínio jurídico, as premissas são normativas e fáticas.

As premissas fáticas são proposições descritivas, passíveis de verdade ou falsidade. Cuida-se de demonstração e verificação empírica. As afirmações empíricas devem ser acompanhadas de argumentos empíricos que demonstrem a satisfação das condições de verdade e certeza do afirmado (ALEXY, 1991, p. 258). Esse assunto diz com a segurança das premissas 
empíricas. Quem afirma que um imóvel deve ser preservado e mantido intocado, porque representativo de valor histórico ou cultural, deve apresentar evidências empíricas seguranças de que essa afirmação é verdadeira.

Quem afirma que um determinado empreendimento não pode ser licenciado sem o prévio estudo de impacto ambiental porque se acha localizado em área de preservação permanente, deve apresentar argumentos empíricos suficientes para justificar a verdade do afirmado. Quem afirma que a jurisprudência sobre a interpretação e classificação jurídicas de uma determinada disposição e situação jurídicas é dominante em certo sentido deve apresentar evidencias empíricas seguras de isso é verdadeiro.

Aqui, novamente, pode ser lembrada a lei epistêmica da ponderação. Quanto maior o grau de intensidade de intervenção ou prejuízo em direito fundamental ou em um princípio, tanto maior deve o ser o grau de segurança ou certeza das premissas empíricas.

Aliás, sobre o assunto, especialmente quando afirmações são lançadas como verdades a partir de dados estatísticos, valiosa é a leitura do Andar do Bêbado de Leonard Mlodinow. As divergências sobre os índices de provimentos dos recursos especiais e extraordinários em matéria penal no Supremo Tribunal Federal e no Superior Tribunal de Justiça referidas, no julgamento das Ações Diretas de Constitucionalidade 43 e 44, que trataram da possibilidade de execução provisória da sentença penal condenatória, depois de julgamento no segundo grau, foram sensíveis.

As premissas normativas devem ser justificadas com argumentos interpretativos, argumentos da dogmática jurídica, argumentos de precedentes e argumentos práticos gerais (argumentos morais, argumentos éticos e argumentos pragmáticos). Não há espaço para aqui serem apresentadas as regras da argumentação jurídica sobre interpretação jurídica, o uso das formulações da dogmática jurídica e o uso dos precedentes ${ }^{2}$. Apenas alguns pontos podem ser destacados.

A interpretação jurídica, aqui entendida como atribuição de significado ao texto dado nas disposições jurídicas, é uma atividade argumentativa. Os argumentos interpretativos são razões que podem ser apresentadas para justificar uma determinada interpretação ${ }^{3}$. Mas interpretação tem limites. Eles são dados pelo texto mesmo. O intérprete somente pode atribuir

\footnotetext{
${ }^{2}$ Sobre as regras da argumentação jurídica, ver Alexy (1991); Gavião Filho (2010).

${ }^{3}$ Sobre os argumentos interpretativos e as regras da interpretação jurídica, ver Gavião Filho (2010, p. 194-206; 2015, p. 117-146); Alexy (1995, p. 71-94).
} 
um dos significados possíveis, o que significa um dos significados que se encontra dentro da chamada franja marginal do texto, conforme o uso corrente da linguagem.

As formulações constantes de uma dogmática jurídica institucionalizada cumprem papel importante para a segurança e certeza nas premissas normativas.

Igualmente, os precedentes desempenham um papel central na justificação das premissas normativas. Na interpretação e aplicação das normas jurídicas para a resolução de casos concretos, a interpretação dada pelos tribunais às disposições jurídicas e às situações jurídicas no passado não pode ser desprezada sem mais. Eles devem ser observados e levados a sério pelos juízes e tribunais em razão do princípio da universalidade e da própria regra formal de justiça. A obediência aos precedentes leva à previsibilidade, estabilidade, confiança e segurança jurídicas. A interpretação e aplicação das normas jurídicas, conforme os casos passados de interpretação e aplicação do Direito, incrementa a previsibilidade da disciplina jurídica das relações sociais. Se os juízes e tribunais mantêm uniformidade na interpretação e aplicação das normas jurídicas em situações semelhantes em seus aspectos relevantes, todos os participantes do sistema normativo terão já condições de prever e antecipar quais serão as qualificações e consequências jurídicas de outras situações igualmente semelhantes em seus aspectos relevantes. Com isso, então, os destinatários e operadores do Direito podem orientar e determinar cursos de ação conforme as formulações interpretativas contidas nos precedentes. Assim, os precedentes consubstanciam a institucionalização da racionalidade prática.

Quanto ao uso dos precedentes, as técnicas da diferenciação e da revisão mostram as vias de não aplicação ou de superação dos precedentes. Em qualquer caso, contudo, devem ser apresentadas razões para a não aplicação ou superação dos precedentes.

A técnica da distinção deixa saber que o intérprete e aplicador do Direito está autorizado a não seguir os precedentes com base no argumento de que o caso que lhe é apresentado para exame e julgamento é faticamente diferente dos casos retratados nos precedentes. Assim, o aplicador do Direito faz uma diferenciação fática dos casos. O juiz ou tribunal pode dizer que o fato que é submetido a julgamento apresenta uma circunstância fática que não estava presente nos precedentes.

A técnica da revisão é empregada para superar ou revogar definitivamente o precedente. Ela implica a rejeição da regra de decisão do precedente. Desse momento em diante, a norma jurídica do precedente até então considerada como tal perde sua condição de ratio decidendi para contar no julgamento dos casos semelhantes em seus aspectos essenciais. 
As premissas normativas, além dos argumentos interpretativos, das formulações da dogmática jurídica e dos argumentos fundados nos precedentes, podem também ser justificadas com base em argumentos morais, argumentos éticos e argumentos pragmáticos.

Com isso, mais uma vez, fica reconhecida a presença de elementos morais na interpretação e aplicação do Direito.

\section{Conclusão}

A investigação tratou da natureza e do conceito de Direito, das formas de aplicação das normas jurídicas e da fundamentação racional da interpretação e aplicação das normas jurídicas na solução de casos concretos.

Na primeira parte, cuidou-se da análise das formulações em torno do conceito e da natureza do Direito a partir da relação entre o Direito e a Moral, com base na tese da separação e na tese da conexão necessária.

A tese da separação é considerada uma das marcas do positivismo jurídico e diz que não há conexão necessária entre Direito e Moral. A validade do Direito positivo não depende da correção moral das normas jurídicas, mas do fato da positividade do Direito.

A tese da separação é a tese mais forte do positivismo jurídico, pois além de negar a conexão necessária entre o Direito e a Moral, afirma que os critérios morais devem ser excluídos na aferição da validade das normas jurídicas. A tese da separação corresponde ao positivismo exclusivo.

A tese da separabilidade é a tese mais fraca do positivismo jurídico. Ela diz que não há relação de necessariedade entre o Direito e Moral, mas admite relação entre o Direito e a Moral. Essa relação é contingente ou convencional, dependendo de o Direito positivo de uma determinada comunidade abarcar ou não princípios morais. Essa é a forma do positivismo inclusivo, que subscreve a tese da incorporação, segundo a qual são conceitualmente possíveis sistemas jurídicos que incluam princípios morais entre os critérios de validades das normas jurídicas. Esse seria o caso do Direito positivo dos Estados de Direito constitucionais, que positivaram nas suas constituições os princípios morais universais da Declaração Universal dos Direitos do Homem.

A tese da conexão necessária entre o Direito e a Moral é uma tese do não positivismo jurídico. Ela diz que a validade das normas jurídicas necessariamente depende de sua conformidade com princípios morais. Uma das formas do não positivismo jurídico é o não 
positivismo jurídico inclusivo. Essa forma do não positivismo jurídico se acha comprometida com a positividade: dado conforme a ordem e eficácia social. A isso, soma-se um terceiro elemento como critério para a validade das normas jurídicas. Exatamente, a correção moral.

O não positivismo inclusivo leva à necessidade de ponderação entre o princípio da segurança jurídica e o princípio da justiça. Já a fórmula da Radbruch extrema injustiça não é Direito é resultado da ponderação entre esses dois princípios.

Com isso, fica demonstrada a relação entre a natureza e o conceito de Direito com a aplicação das normas jurídicas e fundamentação das decisões judiciais de interpretação e aplicação do Direito na solução de casos concretos. Todo o intérprete e aplicador do Direito adota um conceito de Direito que se identifica na prática jurídica.

A presença de princípios morais na natureza e no conceito de Direito, na identificação das fontes do Direito e na interpretação das normas jurídicas coloca a exigência de avaliações morais na aplicação do Direito pelos juízes e tribunais na solução de casos concretos.

Daí, então, a exigência de que o raciocínio jurídico de aplicação das normas jurídicas abarque também argumentos morais. Na subsunção, na analogia e na ponderação, avaliações morais são necessárias. Disposições jurídicas com palavras como "liberdade”, "igualdade”, “dignidade”, “razoabilidade”, “crueldade”, entre tantas outras que podem ser rastreadas no Direito positivado, não podem ser aplicadas sem a presença de argumentos morais.

As razões de fundamentação da interpretação e aplicação das normas jurídicas são, além de pragmáticas e éticas, também razões morais.

Por isso mesmo, então, a fundamentação racional da interpretação e aplicação das normas jurídicas coloca a necessidade de argumentação correta, o que significa apresentação de razões conforme as regras da racionalidade discursiva.

\section{Referências bibliográficas}

ALEXY, Robert. Theorie der juristischen Argumentation. 2. Aufl. Frankfurt am Main: Suhrkamp, 1991.

The Argument from Injustice. Trans. Stanley L. Paulson and Bonnie Litschewski Paulson. Oxford: Oxford University, 2002. 
. Não positivismo inclusivo. In: ALEXY, Robert; BAEZ, Narciso Leandro Xavier; NERY

DA SILVA, Rogério Luiz (Org.). Dignidade humana, direitos sociais e não positivismo inclusivo. Florianópolis: Qualis, p. 303-317, 2015.

. Juristische Interpretation. In: ALEXY, Robert. Recht, Vernunft, Diskurs. Frankfurt am Main: Suhrkamp, S. 71-94, 1995.

. Die logische Analyse juristischer Entscheidung. In: ALEXY, Robert. Recht, Vernunft, Diskurs. Frankfurt am Main: Suhrkamp, S. 13-51, 1995.

. Rechtssystemns und praktische Vernunft. ALEXY, Robert. Recht, Vernunft, Diskurs. Frankfurt am Main: Suhrkamp, S. 213-231, 1995.

. A fórmula peso. In: ALEXY, Robert. Constitucionalismo discursivo. Trad. Luís Afonso Heck. Porto Alegre: Livraria do Advogado, p. 131-153, 2007.

. On the Thesis of a Necessary Connection between Law and Morality: Bulygin's Critique. Ratio Juris, v. 12, n. 13, Jun., p. 138-147, 2000.

. On the Structure of Legal Principles. Ratio Juris, v. 13, n. 3. Sept., p. 294-304, 2000.

. On Balancing and Subsumption. A Structural Comparison. Ratio Juris, v. 16, n. 4, Dec. p. 433-449, 2003.

. On the concept and the nature of law. Ratio Juris, v. 21, p. 281-299, 2008.

. The Nature of Legal Philosophy. Ratio Juris, v. 17, p. 156-167, 2004.

BOROWSKI, Martin. La estrutura de los derechos fundamentales. Trad. Carlos Bernal Pulido. Bogotá: Universidad Externado de Colômbia, 2003.

COLEMAN, Jules. Negative and positive positivism. Journal of Legal Studies, p. 139-164, 1982.

DWORKIN, Ronald. Taking Rights Seriously. Cambridge: Harvard University Press, 1978.

. The Models of Rules I. In: DWORKIN, Ronald. Taking Rights Seriously. Cambridge: Harvard University Press, p. 14-45, 1978a.

GAVIÃO FILHO, Anizio Pires. Colisão de direitos fundamentais, argumentação $e$ ponderação. Porto Alegre: Livraria do Advogado, 2010.

Interpretação como argumentação. In: HECK, Luís Afonso. Direitos fundamentais, teoria dos princípios e argumentação. Porto Alegre: Sergio Antonio Fabris, p.117-146, 2015.

. Regras da ponderação racional. In: HECK, Luís Afonso. Direitos fundamentais, teoria dos princípios e argumentação. Porto Alegre: Sergio Antonio Fabris, p.147-175, 2015.

HABERMAS, Jürgen. Wharheit und Rechtfertigung. Frankfurt am Main: Suhrkamp, 1999.

Theorie des kommunikativen Handelns. Band 1. Frankfurt am Main: Suhrkamp, 1987.

Teorias do Direito e Realismo Jurídico | e-ISSN: 2525-9601 | Salvador | v. 4 | n. 1 | p. 1-18 | Jan/Jun. 2018 
HART, H. L. A. The Concept of Law. London: Oxford University Press, 1961.

KELSEN, Hans. Reine Rechtslehre. Wien: Franz Deuticke, 1960.

Allgemeine Theorie der Normen. Wien: Manzsche Verlags - und Universitätsbuchhandlung, 1979.

. O que é positivismo jurídico? Trad. LuíS Afonso Heck. In: HECK, Luís Afonso. Direito natural, direito positivo, direito discursivo. Porto Alegre: Livraria do Advogado, p. 85-94, 2010.

MacCORMICK, Neil. Rhetoric and the rule of Law. Oxford: Oxford University Press, 2005. MOTTA, Francisco José Borges. Ronald Dworkin e decisão jurídica. Salvador: Juspodivm, 2017.

POSCHER, Ralf. The principles theory: how many theories and what is their merit? In: KLATT, Matthias Institutionalized Reason: the jurisprudence of Robert Alexy. Oxford: Oxford University Press, 2012, p. 218-247.

RADBRUCH, Gustav. Leys que no son derecho y derecho por encima de las leys. In: PANIAGUA, José Maria Rodrigues. Derecho injusto y derecho nulo. Trad. José Maria Rodrigues Paniagua. Madrid: Aguilar, p. 3-21, 1971.

RAZ, Joseph. Between Authority and Interpretation. Oxford: Oxford University Press, 2009. . The argument from Justice, or How Not to Replay to Legal Positivism. In:

STRECK, Lenio Luiz. Jurisdição constitucional e decisão jurídica. 4 ed. São Paulo: Editora Revista dos Tribunais, 2014.

WALUCHOW, W. J. Inclusive legal positivism. Oxford: Clarendon Press, 1994. 